\title{
Optimal Energy Harvesting From a Multistrings PV Generator Based on Artificial Bee Colony Algorithm
}

\author{
Saad Motahhir (), Aissa Chouder, Aboubakr El Hammoumi ${ }^{(0)}$, Abou Soufiane Benyoucef, Abdelaziz El Ghzizal, \\ Sofiane Kichou, Kamel Kara, Padmanaban Sanjeevikumar ${ }^{\circledR}$, Senior Member, IEEE, \\ and Santiago Silvestre, Senior Member, IEEE
}

\begin{abstract}
Photovoltaic (PV) systems based on multistring configuration are the best effective solution, given its advantages in terms of system availability, reliability, and energy efficiency. In this particular configuration each substring has its own dc-dc converter and a dedicated maximum power search algorithm which increase the cost and complexity. In this article, an efficient centralized global maximum power tracking (GMPPT) algorithm for multistring PV array subject to partial shading conditions is proposed. The algorithm is based on artificial bee colony (ABC) as an optimization approach to provide the optimal duty cycles allowing the extraction of the optimal global maximum power from each substring. In particular, the proposed approach allows significant reduction of the required sensors to only one pair of current and voltage sensors, at the common point of connection of the overall PV strings. The simulation study has been carried out under Cadence/Pspice and MATLAB/Simulink platforms on the I-V curves to confirm the effectiveness of the proposed algorithm when several shading patterns occur. In addition, complex shading pattern of a daily profile has been also carried out to demonstrate the GMPPT finding in dynamically variable conditions. Performance comparison against particle swarm optimization based maximum power point tracking algorithm and the traditional perturb and observe method has also been carried out. The obtained simulation and experimental results have shown the effectiveness and a good tracking capability of the proposed $\mathrm{ABC}$ algorithm in a multistring $P V$ array configuration under uniform and nonuniform irradiance.
\end{abstract}

Index Terms-Artificial bee colony (ABC) algorithm, digital signal processor (DSP), global maximum power tracking

Manuscript received March 26, 2020; revised May 12, 2020; accepted May 23, 2020. (Corresponding author: Saad Motahhir.)

Saad Motahhir is with the Engineering, Systems, and Applications Laboratory, ENSA, SMBA University, Fez 30080, Morocco (e-mail: saad.motahhir@usmba.ac.ma).

Aissa Chouder is with the Electrical Engineering Laboratory, University Mohamed Boudiaf of M'sila, Msila 28000, Algeria (e-mail: aissachouder@gmail.com).

Aboubakr El Hammoumi and Abdelaziz El Ghzizal are with the Innovative Technologies Laboratory, EST-Sidi Mohamed Ben Abdellah University, Fez 30000, Morocco (e-mail: aboubakr.elhammoumi@usmba.ac.ma; abdelaziz.elghzizal@usmba.ac.ma).

Abou Soufiane Benyoucef is with the University Djilali Bounaama, Khemis Miliana 44225, Algeria (e-mail: benyoucefsoufiane@ gmail.com).

Kamel Kara is with the SET Laboratory, Department of Electronics, Blida University, Blida BP 270, Algeria (e-mail: k.kara68@gmail.com).

Padmanaban Sanjeevikumar is with the Department of Energy Technology, Aalborg University 9100, Aalborg, Denmark (e-mail: san@et.aau.dk).

Santiago Silvestre is with the Department of Electronic Engineering, Universitat Politècnica de Catalunya 08034, Barcelona, Spain (e-mail: santiago.silvestre@upc.edu).

Sofiane Kichou is with the University Centre for Energy Efficient Buildings, Czech Technical University in Prague, Třinecká 1024, 27343 Buštěhrad, Czech Republic (e-mail: kichousofiane@gmail.com).

Digital Object Identifier 10.1109/JSYST.2020.2997744
(GMPPT), multistring photovoltaic (PV) array, partially shading conditions (PSC).

\section{INTRODUCTION}

$\mathbf{E}$ LECTRIC power generation from grid-connected and standalone photovoltaic (PV) plants has seen a spectacular increasing rate in the last decade, where a global solar installation of $509 \mathrm{GW}$ has been reached in 2018 and is expected to reach 1,296 GW in 2023 [1]. In spite of this important installed PV capacity, low energy yields due to poor power management at PV array and power processing unit levels are still an open problem [2]-[4].

Common configuration of grid-connected PV systems consists of using a central inverter with a dc-dc converter responsible for the extraction of the maximum available power of the whole PV array. However, this topology is highly sensitive to mismatch and the presence of partial shadows in the PV array, where significant power losses may occur [5]. Another scheme of PV array configuration consists of using multistrings topology with distributed dc-dc converters allowing continuous service of the whole PV array or a part of it and consequently minimizing power losses [6]-[8]. In such topology, each PV string is connected with an independent dc-dc converter with its dedicated maximum power point tracking (MPPT) algorithm, resulting in efficient extraction of the total available power [9], [10]. There are two configuration types of dc-dc converters in a multistrings PV system; series or parallel output configuration. However, the system with series configuration may have a problem of crosscoupling, where the failure of one of the converters interrupts the operation of the others.

Whatever the chosen topology, the maximum power extraction is likely compromised due to the apparition of multiple local maxima caused by the partial shadows present on the plane of the PV generator. In such circumstances, conventional MPPT algorithms, such as perturb and observe method (P\&O) [11], [12] or incremental conductance [13], [14], fail to track the global maximum point. To overcome the weaknesses of the conventional MPPT algorithms, several works have pointed out the advantages of using multistring topology with distributed dcdc converters based on global maximum power point tracking (GMPPT) algorithms [15]-[17]. For instance, advanced techniques based on artificial neural networks [18], [19], fuzzy logic [20], [21], dividing rectangle search control [22], sequential extremum seeking control [23], [24] have been used successfully in finding the global maximum power point (GMPP). In 


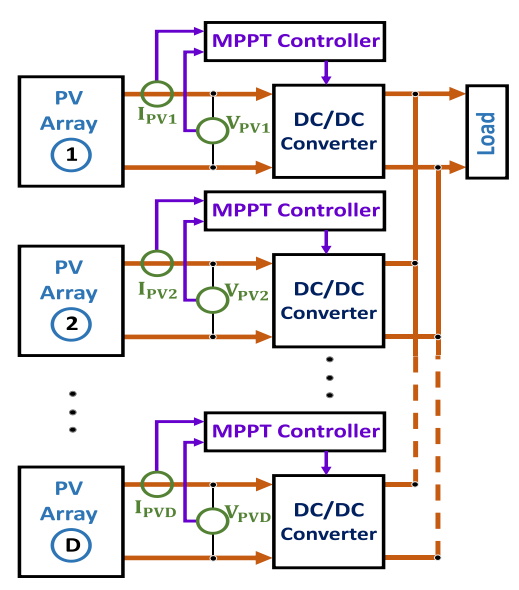

Fig. 1. Multistring PV system controlled by multiple MPPT controllers.

recent years, bioinspired optimization methods such as particle swarm optimization (PSO) [25]-[29], ant colony optimization (ACO) [30], [31], and artificial bee colony (ABC) [32], [33], [34] showed effectiveness in the determination of GMPP. In a previous work by Benyoucef et al. [32], a novel ABC-based MPPT using direct duty cycle control method for PV systems has been proposed. It has been shown that the proposed algorithm allows finding the GMPP under partially shaded and variable meteorological conditions with better tracking performances. In [32], the focus was in optimizing the output power of only one PV module or only a group of PV modules arranged in one string subject to partial shading conditions where the $\mathrm{ABC}$ algorithm works in a I-D search approach to provide the optimal duty cycle for the dc-dc converter. While in this artcle, the focus is on the multistring topology where each string is connected to a dc-dc converter. Regarding this configuration the aim is to derive the optimal duty cycle for each substring with only one central MPPT controller where the ABC algorithm operates in a multidimensional search approach such as highlighted in Fig. 2. Unlike the conventional method depicted in Fig. 1, where each dc-dc converter has its own search algorithm, the proposed scheme allows cost reduction and lower complexity. It is worth to mention here that this cost-effective solution allows the extraction of the real available global maximum power of each string and requires only one pair of current and voltage sensors at the common point of connection (see Fig. 2). The developed GMPPT control strategy based on the ABC optimization algorithm has been validated by a simulation study considering various I-V curves with different locations of the GMPP and by introducing a complex shading pattern on a daily irradiance profile. Experimental validation of the proposed multidimensional search algorithm has also been performed with a low-cost digital signal processor (DSP) board. In addition, the proposed control approach presented good results when compared with two other MPPT control strategies based on P\&O and PSO algorithms, respectively, using the same shading patterns.

The rest of this article is organized as follows. Section II provides an overview of PV system configuration investigated in the present work. Section III gives the ABC algorithm description and its adaptation to GMPP finding. Section IV shows simulation and experimental results of the proposed method. A comparison of the proposed method with the PSO-based MPPT

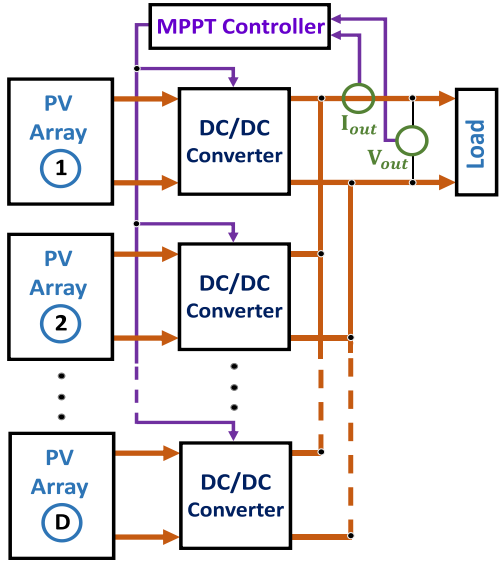

Fig. 2. Multistring PV system controlled by a single MPPT controller.

and the traditional $\mathrm{P} \& \mathrm{O}$ algorithm is also depicted in this section. Finally, Section V concludes this article.

\section{Multistrings PV SYSTEM CONFIGURATION}

Parallel connected dc-dc converters topology in multistring configuration of PV plants, shown in Fig. 1, is an effective solution in terms of flexibility of module layout, redundancy in case of source or converter failure, easier and safer installation and maintenance, and lower sensitivity to nonuniform illumination [32], [35], [36]. In such PV plant arrangement, the MPPT algorithm is commonly performed individually for each string that gives best energy harvesting. However, the main drawback of such configuration is the involved number of current and voltage sensors, especially when the number of PV strings is relatively high. An alternative solution presented in Fig. 2 allows using only one pair of current and voltage sensors to derive the maximum power from the whole PV system. Thus, the central maximum power point (MPP) controller senses the output voltage and the output current of the common dc bus and controls the individual dc-dc converters in such way to get the overall optimal power point. On the other hand, such control scheme is more appropriate when multidimensional search objective is targeted. Many researchers have used multistring configuration and advanced meta-heuristic algorithms to deal with MPPT based on central controller concept. For example, Miyatake et al . [27] have evaluated the PSO-based MPPT, Keyrouz and Georges [37] have proposed the combination of Bayesian fusion and PSO and Jiang et al. [30] have evaluated the ACO-based MPPT. In this article, multistring PV system is used to evaluate the MPPT based on $\mathrm{ABC}$ algorithm by using direct duty cycle control approach.

\section{ABC BASED GMPPT FOR MULTISTRING TOPOLOGY}

The $\mathrm{ABC}$ algorithm emulates the natural foraging behavior of honey bees to solve multidimensional and multimodal optimization problems [38], [39]. In the field of PV systems, the $\mathrm{ABC}$ showed effectiveness in the estimation of solar cell model parameters [40], [41], and also in the MPPT controller [32].

In the $\mathrm{ABC}$ algorithm, the solutions of optimization problems are food sources represented by the three different classes of honey bees (employed, onlooker, and scout bees). The employed 
bees are assigned to find and exploit food sources and share the information with onlooker bees. Probably the latter will choose the food sources of higher quality. While, employed bees whose food sources are relatively low become scoots, their food sources are abandoned, and they will explore for new food sources.

The same steps published in [32] are followed to implement the ABC-based GMPPT of a single string PV system. However, in the present work, the $\mathrm{ABC}$ algorithm has been modified in order to control each string's dc-dc converter to get the optimal generated dc power, even in partial shading conditions.

The duty cycles of dc-dc converters are considered as the control variables responsible for the determination of the maximum power produced by the whole PV array. Thus, in the adapted $\mathrm{ABC}$ algorithm, each candidate solution is chosen as a vector of duty cycle values $d_{i}^{j}$ of dc-dc converters as follows:

$$
\begin{aligned}
d_{i}^{j} & =d_{\min }^{j}+\operatorname{rand}[0,1]\left(d_{\max }^{j}-d_{\min }^{j}\right) \\
\text { with: } i & =1,2, \ldots, \mathrm{SN} j=1,2, \ldots, D \\
\text { new_d } d_{i}^{j} & =d_{i}^{j}+\phi_{i}^{j}\left(d_{i}^{j}-d_{k}^{j}\right)
\end{aligned}
$$

where $d_{\min }^{j}$ and $d_{\max }^{j}$ are the minimum and the maximum limit of the duty cycles search range of the converter $j, D$ represents the number of PV strings, $\mathrm{k}$ is the index of the previous duty cycle and $\mathrm{SN}$ is the number of candidates.

The fitness of each solution (duty cycles vector) is defined by the probability $P_{i}$ given in the following expression.

$$
P_{i}=\frac{P_{\text {load }_{i}}}{\sum_{i=1}^{\mathrm{SN}} P_{\text {load }_{i}}}
$$

To evaluate the duty cycles, the controller generates pulsewidth modulation signals considering the value of $d_{i}^{j}$. The corresponding output power $d_{\operatorname{load}_{j}}$ is then calculated from the product of the measured output current and voltage.

In practical conditions, the real working environment of the PV system is always changing due to the varying weather conditions, and as a result, the global MPP is always changing. So, the MPPT algorithm must be able to search for a global MPP for the new weather condition. For this purpose, the search process has to restart with a total reinitialization whenever the weather conditions are changed. Here, we use the (4) to detect these changes

$$
\frac{\left|P p v_{\text {new }}-P p v_{\text {last }}\right|}{P p v_{\text {last }}} \geq \Delta P p v(\%)
$$

Finally, steps related to the implementation of the ABC algorithm are summarized in the flowchart presented in Fig. 3.

\section{IMPLEMENTATION AND RESULTS}

The PV system presented in Fig. 4 was designed and implemented to examine the effectiveness of the proposed multidimensional optimization algorithm. The total power of the PV array is $320 \mathrm{~W}$ arranged in two parallel strings where each one is formed by two PV modules serially connected. The optimal power matching is achieved by two dedicated dc-dc boost converters sharing the same dc bus. As previously stated, only one MPPT controller is responsible to deliver the corresponding duty cycles by measuring only the current and voltage of the shared dc

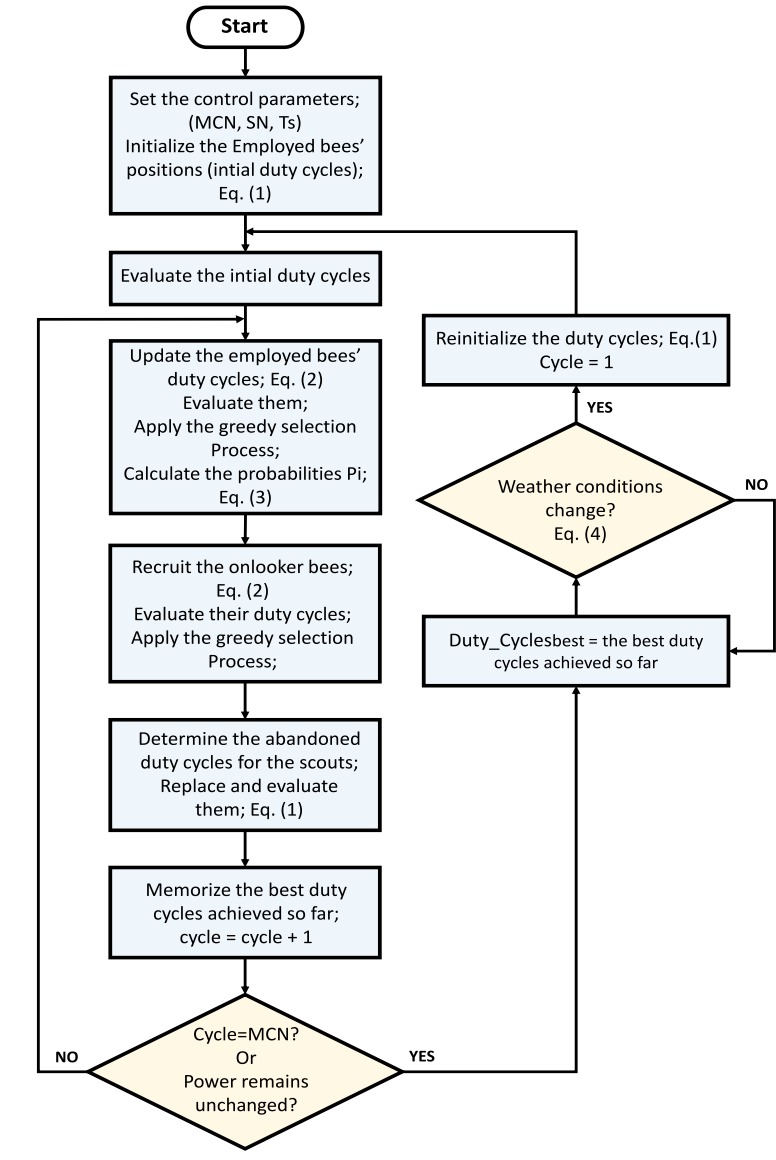

Fig. 3. Flowchart of the ABC-based MPPT controller.

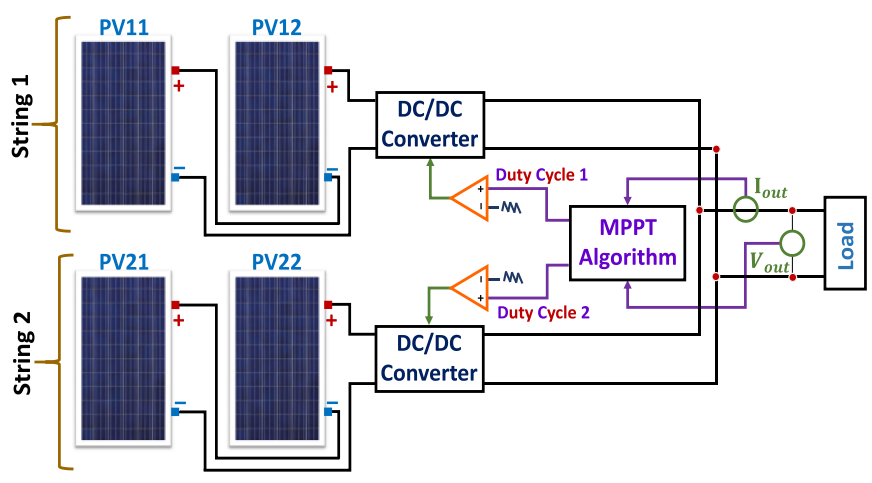

Fig. 4. System block diagram.

load. In Table I, it is reported the main electrical characteristics of the used PV module.

\section{A. Simulation Setup}

The present section will focus on the simulation study to assess the ability of the proposed optimization algorithm to effectively localize the GMPP in case of multistring PV array configuration. Toward this end, the physical parts, such as the PV array and the $\mathrm{dc}-\mathrm{dc}$ boost converters, are simulated in Cadence/Pspice software while the MPPT controller is implemented in MATLAB/Simulink tool. Moreover, a comparative assessment against well-known control algorithms such as PSO 
TABLE I

BP SX 80 PANEL SPECIFICATIONS AT STC

\begin{tabular}{lc}
\hline \hline Characteristic & Value \\
\hline maximum power & $80 \mathrm{~W}$ \\
open-circuit voltage & $22.1 \mathrm{~V}$ \\
maximum power voltage & $17.6 \mathrm{~V}$ \\
short circuit current & $4.8 \mathrm{~A}$ \\
maximum power current & $4.6 \mathrm{~A}$ \\
temperature coefficient & $-0.080 \mathrm{~V} /{ }^{\circ} \mathrm{C}$ \\
configuration & $2 \mathrm{~S} 1 \mathrm{P}(2$ bypass diodes $)$ \\
\hline
\end{tabular}

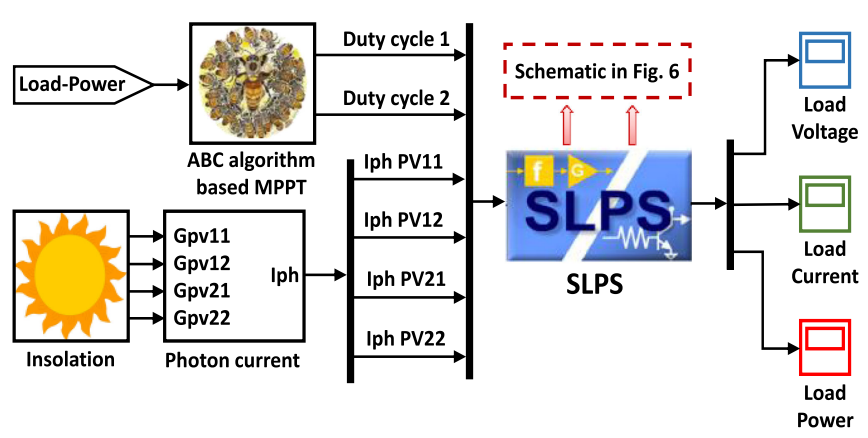

Fig. 5. Simulink model of ABC-based MPPT controller.

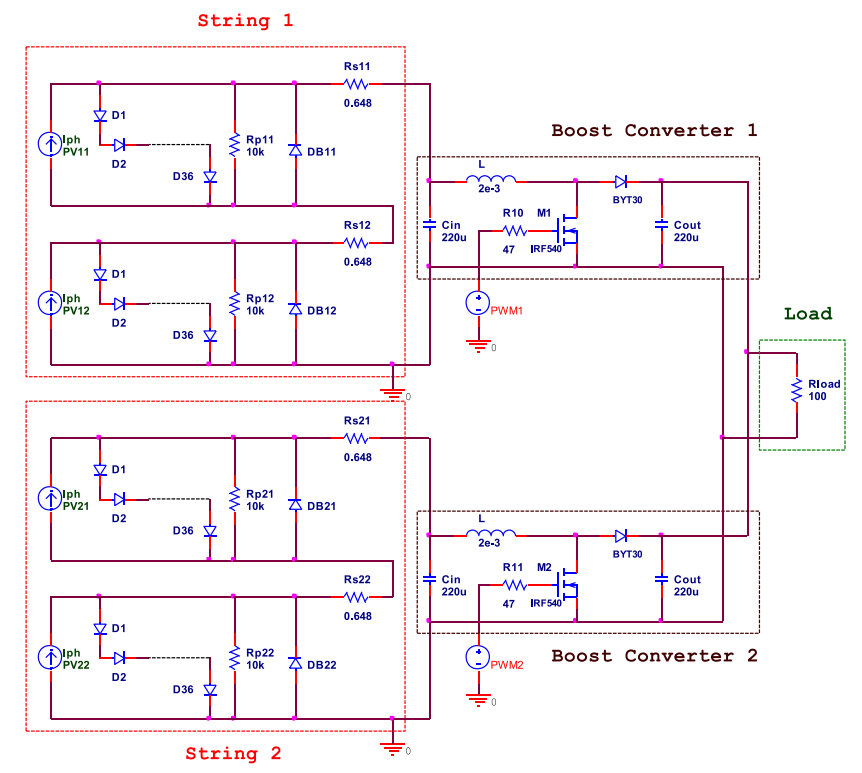

Fig. 6. Pspice circuit of PV arrays and boost converters.

and $\mathrm{P} \& \mathrm{O}$ is also carried out in this section. Figs. 5 and 6 depict the implementation of the studied PV system in both software environments where the SLPS bloc is responsible for the synchronization between MATLAB and Pspice.

1) Simulation-Based Design of the ABC Method: Actually, the possible solutions ( $\mathrm{SN}$ ) are a key parameter involved in the convergence speed and the tracking capabilities of the $\mathrm{ABC}$ method. Thus, a high number of bees surely converge toward the real MPP but at the cost of excessive calculation time. On the other hand, fewer bees could bring to the GMPP but at the cost of slower convergence rate. To handle this problem, an in-depth simulation study was done in order to choose adequate

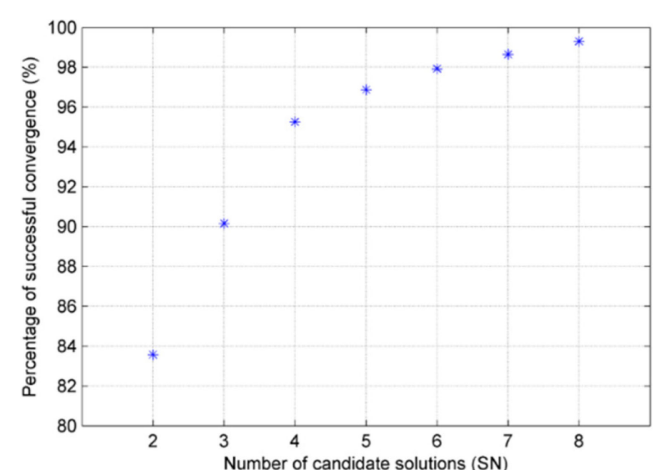

Fig. 7. Candidate solutions $(S N)$ versus convergence rate.

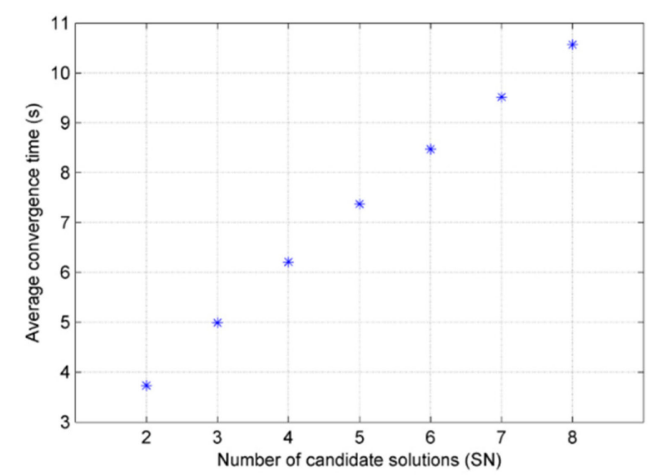

Fig. 8. Candidate solutions $(S N)$ versus average convergence time.

TABLE II

CHARACTERISTICS OF ABC, PSO, AND P\&O MPPT METHODS

\begin{tabular}{cccccc}
\hline \hline \multicolumn{2}{c}{$\mathrm{ABC}$} & \multicolumn{2}{c}{$\mathrm{PSO}$} & \multicolumn{2}{c}{$\mathrm{P} \& \mathrm{O}$} \\
\hline $\mathrm{Ts}$ & $0.0 \mathrm{~s}$ & $\mathrm{Ts}$ & $0.05 \mathrm{~s}$ & $\mathrm{Ts}$ & $0.01 \mathrm{~s}$ \\
$\Delta \mathrm{P}_{\mathrm{PV}}$ & $2 \%$ & $\Delta \mathrm{P}_{\mathrm{PV}}$ & $2 \%$ & $\Delta \mathrm{P}_{\mathrm{PV}}$ & $2 \%$ \\
$\mathrm{SN}$ & 4 & $\mathrm{~Np}$ & 4 & $\Delta \mathrm{dc}$ & 0.01 \\
$\mathrm{MCN}$ & 30 & $\mathrm{MCN}$ & 30 & - & - \\
- & & $\mathrm{W}$ & 0.4 & - & - \\
- & & $\mathrm{Cl}$ & 1.2 & - & - \\
\hline
\end{tabular}

candidate solutions ( $\mathrm{SN}$ ) on the basis of a tradeoff between speed convergence and convergence rate. The simulation results presented in Figs. 7 and 8 give the evolution of the convergence rate and average time convergence versus candidate solutions, respectively. Based on these results, $\mathrm{SN}=4$ has been chosen as a number of candidates $(\mathrm{SN})$ in this article.

The key parameters of the implemented MPPT algorithms (ABC, PSO, and P\&O) are presented in Table II.

2) Test With Different Shading Scenarios: In order to check the efficiency of the proposed method and power harvesting capabilities, a simulation study was performed under uniform and partial shading conditions. Toward this end, the PV generator was divided into four submodules; PV11 and PV12 for the first string and PV21 and PV22 for the second string (see Fig. 6). Then, three preselected shading patterns listed in Table III and denoted as SP1, SP2, and SP3, were simulated in order to highlight the GMPP tracking under transient shading. The simulation results presented in Fig. 9 give the power evolution 
TABLE III

CONSIDERED SHADING PATTERNS

\begin{tabular}{cc}
\hline \hline $\begin{array}{c}\text { Pattern } \\
\mathrm{N}^{\circ}\end{array}$ & $\begin{array}{c}\text { Irradiance }(\mathrm{G}) \text { on PV modules } \\
{[\mathrm{Gpv} 11, \mathrm{Gpv} 12, \mathrm{Gpv} 21, \mathrm{Gpv} 22]\left(\mathrm{W} / \mathrm{m}^{2}\right)}\end{array}$ \\
\hline $\mathrm{SP} 1$ & {$[1000,1000,1000,1000]$} \\
$\mathrm{SP} 2$ & {$[1000,1000,1000,250]$} \\
$\mathrm{SP} 3$ & {$[250,1000,1000,100]$} \\
\hline
\end{tabular}
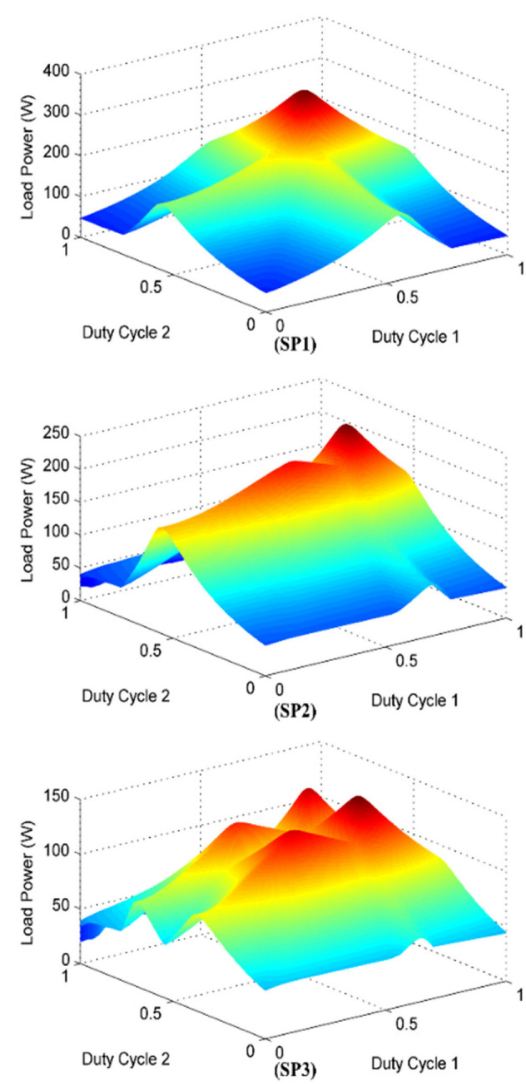

Fig. 9. Load power versus duty cycles for the three shading patterns.

at the shared dc bus for each of the three patterns, SP1, SP2, and SP3, respectively.

The tracking performances of the proposed algorithm under varying shading patterns were also illustrated by considering a moving shade over the two strings. To this end, two case studies were proposed.

1) Case 1: The shading pattern moves from SP1 to SP2.

2) Case 2: The shading pattern moves from SP1 to SP3.

The simulation results shown in Figs. 10 and 11 depict the dynamic response of the load power and the corresponding duty cycles for cases 1 and 2. According to these plots, it is clearly shown that once the shading pattern changes from a uniform condition to a nonuniform condition at $10 \mathrm{~s}$, the proposed method can track the GMPP corresponding to the new environmental condition.

3) Performance Comparison: The aim of this section is to compare the performances of the proposed multidimensional ABC-based MPPT controller with well-known existing MPPT techniques such as PSO and P\&O. The main parameters of each MPPT algorithm are listed in Table II. Actually, to get a reliable and trusted comparison study, the simulations were

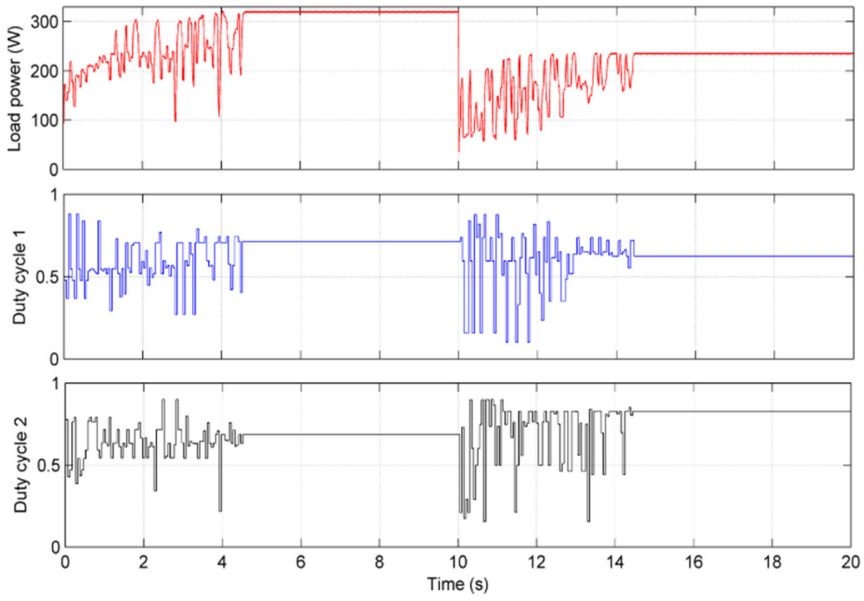

Fig. 10. Change from SP1 to SP2.
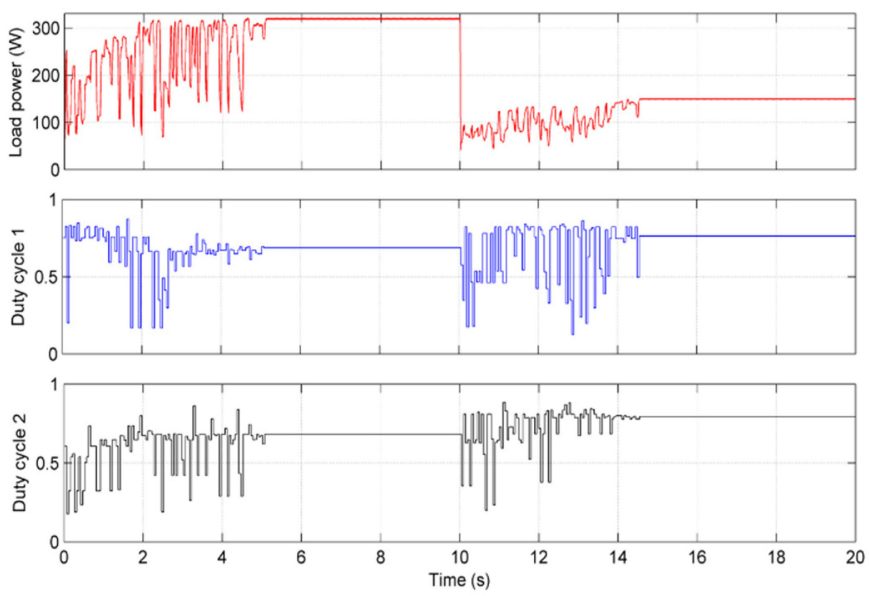

Fig. 11. Change from SP1 to SP3.

TABLE IV

Characteristics OF ABC, PSO, AND P\&O MPPT METHODS

\begin{tabular}{cccccc}
\hline \hline $\begin{array}{c}\text { Shading } \\
\text { pattern }\end{array}$ & $\begin{array}{c}\text { Tracking } \\
\text { algorithm }\end{array}$ & $\begin{array}{c}\text { Mean } \\
\text { power } \\
(\mathrm{W})\end{array}$ & $\begin{array}{c}\text { Tracking } \\
\text { speed (s) }\end{array}$ & $\begin{array}{c}\text { Optimal } \\
\text { power } \\
(\mathrm{W})\end{array}$ & $\begin{array}{c}\text { Efficiency } \\
(\%)\end{array}$ \\
\hline \multirow{4}{*}{ PS1 } & ABC & 319.26 & 5.88 & & 99.87 \\
& PSO & 319.89 & 4.50 & 320.00 & 99.96 \\
& P\&O & 319.68 & 2.02 & & 99.90 \\
PS2 & ABC & 235.22 & 5.60 & & 99.60 \\
& PSO & 230.76 & 5.10 & 237.12 & 97.32 \\
& P\&O & 202.04 & 1.64 & & 85.20 \\
PS3 & ABC & 151.61 & 6.10 & & 99.26 \\
& PSO & 144.61 & 5.60 & 154.29 & 93.72 \\
& P\&O & 93.59 & 1.44 & & 60.66 \\
\hline
\end{tabular}

executed 200 times for each MPPT algorithm under shading patterns given in Table III. The comparison results, reported in Table IV, reveals the superiority of the proposed multidimensional ABC algorithm in terms of accuracy compared to PSO and P\&O algorithms. However, a minor difference with respect to the average response time is reported between $\mathrm{ABC}$ and PSO methods. Where the ABC based-MPPT method has a slow tracking speed compared to the PSO based-MPPT method.

To complete this comparison study, the performances of each MPPT algorithm was tested in terms of daily power production 


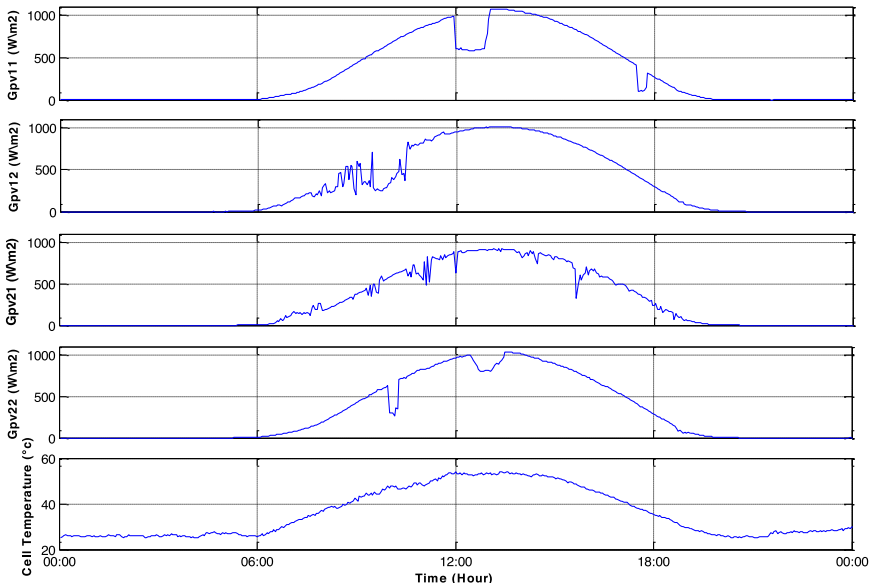

Fig. 12. Weather daily profiles used.

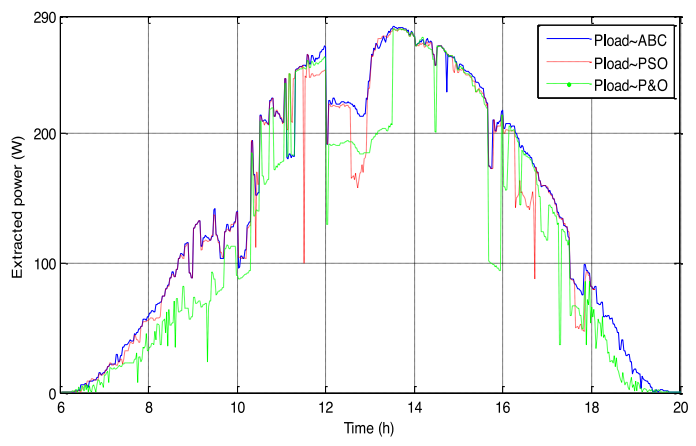

Fig. 13. Simulation results of the extracted powers using ABC, PSO, and $\mathrm{P} \& \mathrm{O}$.

by considering a nonuniform daily irradiance. Toward this end, the simulations were performed under varying daily irradiance and temperature profile, as shown in Fig. 12. Fig. 13 depicts the simulation results of the obtained output power when applying $\mathrm{ABC}, \mathrm{PSO}$, and $\mathrm{P} \& \mathrm{O}$ MPPT algorithms in case of daily varying irradiance and temperature profiles. The results clearly show the power harvesting of the proposed multidimensional $\mathrm{ABC}$ algorithm due to the successful location of the GMPP when nonuniform irradiance occurs, whereas PSO algorithm did not always succeed to locate it. In terms of power harvesting, the proposed algorithm gives more than $3.58 \%$ compared to PSO algorithm. This result confirms the weakness of the PSO algorithm to always track the GMPP and prove that it can be trapped in local minima. $\mathrm{P} \& \mathrm{O}$ power tracking algorithm shows less generated power compared to meta-heuristic search techniques. This is mainly due to the inherent inability of the algorithm to find the GMPP when the power curve exhibits multiple MPPs. In order to quantify, the power gain obtained by the abovementioned algorithms, the hourly array yield (YA) indicator was calculated using (5). Indeed, the hourly array yield (YA) is the hourly output energy of the PV array divided by the peak power of the PV arrays, where $n$ is the number of samples. The result reported by the bar graph of Fig. 14 reveals that in all situations the proposed algorithm gives much more output power.

$$
Y_{A}=\frac{\sum_{n=1}^{n} P_{P V \text { array }} / n}{P_{P V \text { array }} \text { peak }}
$$

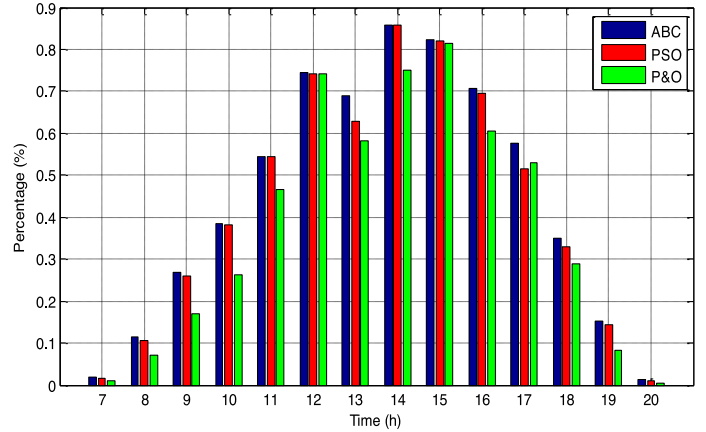

Fig. 14. Hourly array yield.

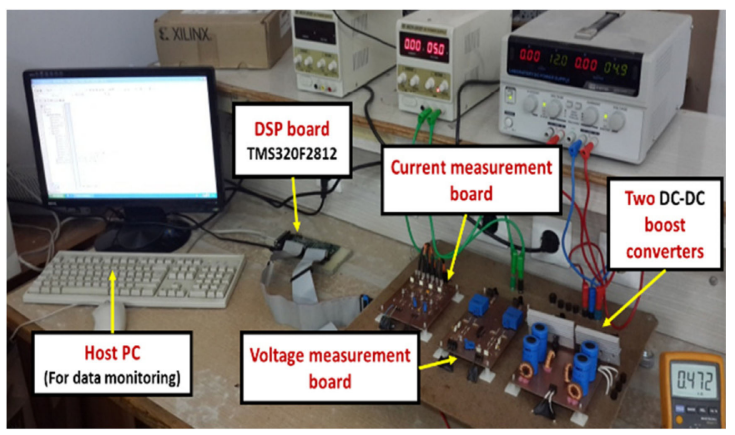

Fig. 15. Test bench of MPPT system.

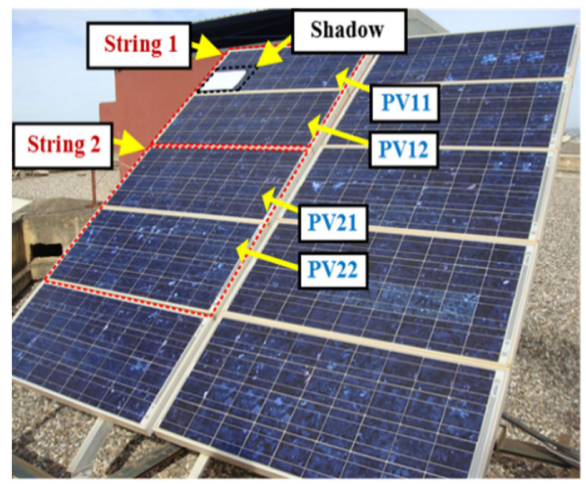

Fig. 16. PV array with an artificial shade.

\section{B. Experimental Results}

The experimental setup devoted to the implementation of the proposed multidimensional ABC-based MPPT is shown in Figs. 15 and 16. In fact, the algorithms were implemented in a low-cost DSP board (TMS320F2812), where the two boost converters are driven at $20 \mathrm{kHz}$. The main parameters of each MPPT algorithm are taken the same as given in Table II. Two real-time tests have been performed as follows.

1) Testing the algorithm tracking capabilities under different shading patterns.

2) Comparing the ABC-based MPPT with the PSO based approach.

In order to consider various shading patterns, some parts of the PV modules have been intentionally occulted by making artificial shade as presented in Figs. 16 and 17(a), (b), and (c) are the patterns considered in this experimental study with one peak (SP1), two peaks (SP2), and three peaks (SP3), respectively. 


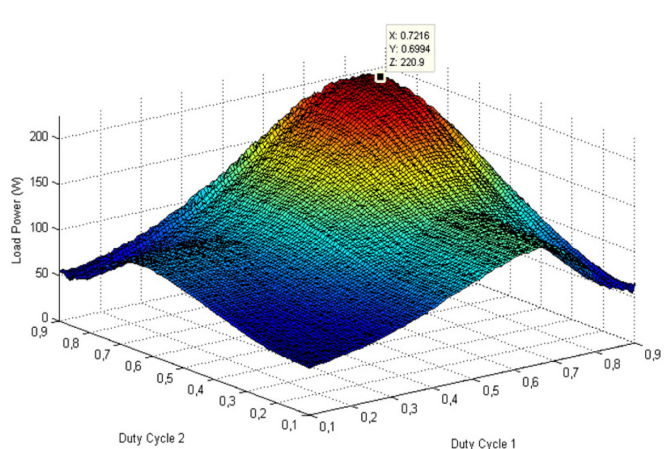

(a)

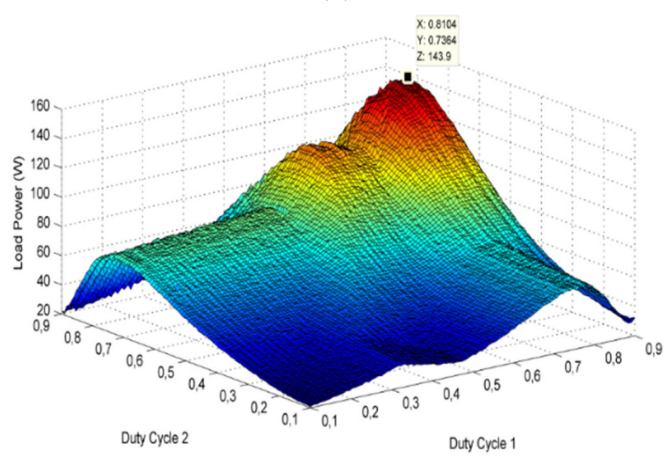

(b)

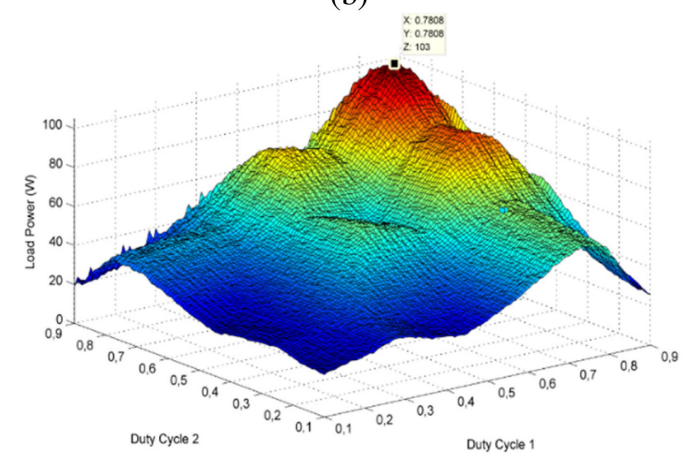

(c)

Fig. 17. Considered shading patterns. (a) SP1. (b) SP2. (c) SP3.
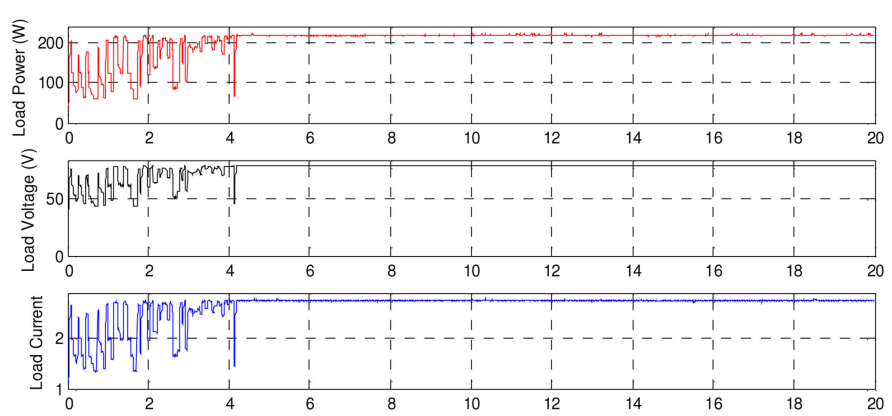

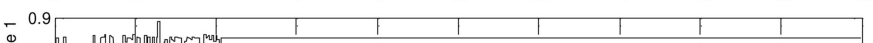

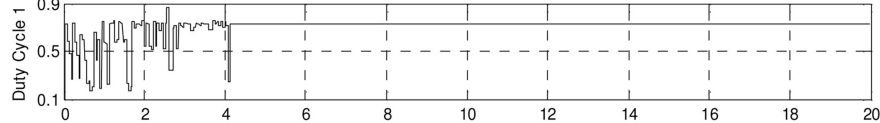

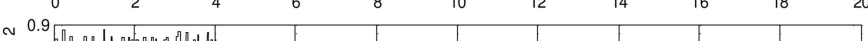

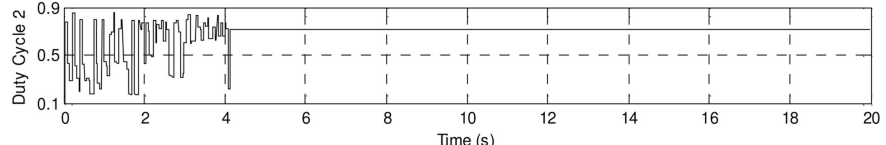

Fig. 18. DSP data under uniform insolation condition.
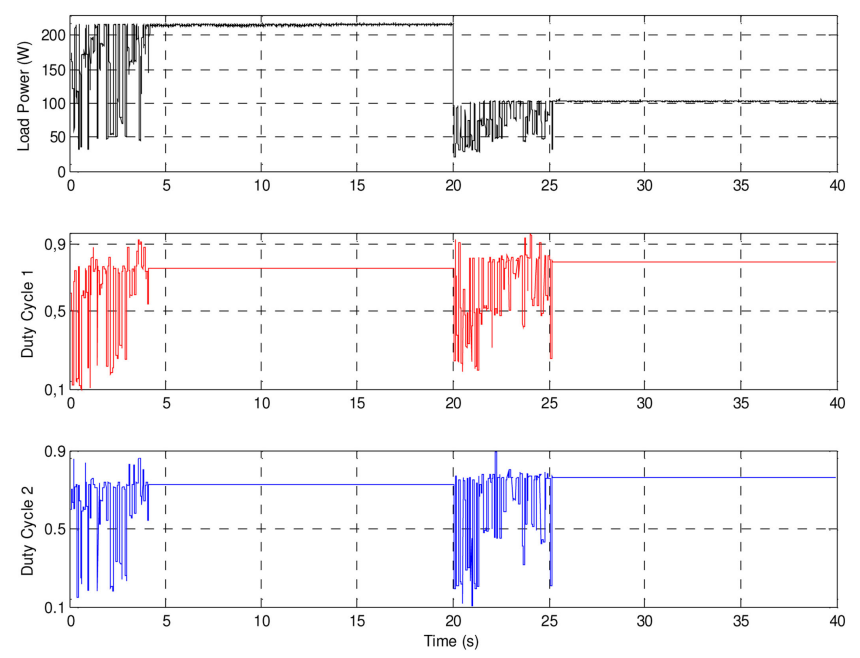

Fig. 19. Performance of the ABC-based MPPT before and during the occurrence of partial shading.

Actually, each shading pattern is obtained by sweeping the duty cycle of the dc converters ranging from $10 \%$ to $90 \%$ with a step change of $0.8 \%$. Then, data obtained from this sweeping procedure are collected by the internal memory of the DSP board and plotted in 3-D using MATLAB "surf" function.

For dynamic performance assessment, two case studies were carried out. In the first case, the PV array was tested under uniform irradiance on a sunny day. The reported output current, output voltage, the load power, and the two converters' duty cycles for this case are reported in Fig. 18. The transient responses, which take about $4 \mathrm{~s}$, denote the search phase of the algorithm. At the steady, all the variables remain unchanged which means that the GMPP is reached successfully. While in the second case, the PV array is left under uniform irradiance until $20 \mathrm{~s}$. After that moment, an intentional shade was applied upon a part of one PV module. The corresponding output power and converters' duty cycles are depicted in Fig. 19. The responses show clearly the tracking capabilities of the proposed algorithm in multistring configuration.

\section{CONCLUSION}

In this article, the capabilities of $\mathrm{ABC}$ optimization algorithm, used in multidimensional based search, to extract the optimal power point from a PV plant arranged in multistring topology was presented. The proposed approach present a cost-effective solution as only one central controller and only one pair of current and voltage sensors were required. The simulation results performed under various shading patterns, either in the case of static I-V curves or in the case of dynamically irradiance changing, the results were very promising and better power harvesting than PSO approach. The experimental results carried out on two strings where the $\mathrm{ABC}$ algorithm was implemented in a low-cost DSP board have also shown the effectiveness and the accuracy of the proposed approach to find the available optimal power from the entire PV system. The proposed solution of extracting the optimal available power in multistring topology can be easily implemented in various practical PV systems 
such as PV grid-connected systems, PV pumping systems, and stand-alone PV systems.

\section{REFERENCES}

[1] "Wind \& solar energy installation data: 2000-2018 Actuals/ 2019-2023 forecast," [Online]. Available: http://www.fi-powerweb.com/RenewableEnergy.html, Accessed: Feb. 20, 2020.

[2] S. Sajadian, R. Ahmadi, and H. Zargarzadeh, "Extremum seeking-based model predictive MPPT for grid-tied Z-source inverter for photovoltaic systems," IEEE J. Emerg. Sel. Topic Power Electron., vol. 7, no. 1, pp. 216-227, Mar. 2019.

[3] M. Killi and S. Samanta, "Voltage-sensor-based MPPT for stand-alone PV systems through voltage reference control," IEEE J. Emerg. Sel. Topic Power Electron., vol. 7, no. 2, pp. 1399-1407, Jun. 2019.

[4] A. El Hammoumi, S. Motahhir, A. Chalh, A. El Ghzizal, and A. Derouich, "Real-time virtual instrumentation of Arduino and LabVIEW based PV panel characteristics," IOP Conf. Ser. Earth Environ. Sci., vol. 161, no. 1, 2018, Art. no. 012019.

[5] F. Bayrak, G. Ertürk, and H. F. Oztop, "Effects of partial shading on energy and exergy efficiencies for photovoltaic panels," J. Cleaner Prod., vol. 164, pp. 58-69, Oct. 2017

[6] A. Woyte, J. Nijs, and R. Belmans, "Partial shadowing of photovoltaic arrays with different system configurations: Literature review and field test results," Sol. Energy, vol. 74, no. 3, pp. 217-233, 2003.

[7] P. A. B. James, A. S. Bahaj, and R. M. Braid, "PV array $<5 \mathrm{kWp}+$ single inverter $=$ grid connected $\mathrm{PV}$ system: Are multiple inverter alternatives economic?," Sol. Energy, vol. 80, no. 9, pp. 1179-1188, Sep. 2006.

[8] A. M. Pavan, S. Castellan, S. Quaia, S. Roitti, and G. Sulligoi, "Power electronic conditioning systems for industrial photovoltaic fields: Centralized or string inverters?," in Proc. Int. Conf. Clean Elect. Power, 2007, pp. 208-214.

[9] N. Femia, G. Lisi, G. Petrone, G. Spagnuolo, and M. Vitelli, "Analysis of photovoltaic systems with distributed maximum power point tracking," in Proc. IEEE Int. Symp. Ind. Electron., 2008, pp. 2408-2413.

[10] M. A. Farahat, H. M. B. Metwally, and A. Abd-Elfatah Mohamed, "Optimal choice and design of different topologies of DC-DC converter used in PV systems, at different climatic conditions in Egypt," Renewable Energy, vol. 43, pp. 393-402, Jul. 2012.

[11] S. Motahhir, A. E. L Hammoumi, A. E. L Ghzizal, and A. Derouich, "Open hardware/software test bench for solar tracker with virtual instrumentation," Sustain. Energy Technol. Assessments, vol. 31, pp. 9-16, Feb. 2019.

[12] T. Esram and P. L. Chapman, "Comparison of photovoltaic array maximum power point tracking techniques," IEEE Trans. Energy Convers., vol. 22, no. 2, pp. 439-449, Jun. 2007

[13] V. Salas, E. Olías, A. Barrado, and A. Lázaro, "Review of the maximum power point tracking algorithms for stand-alone photovoltaic systems," Sol. Energy Mater. Sol. Cells, vol. 90, no. 11, pp. 1555-1578, Jul. 2006.

[14] S. Motahhir, A. El Hammoumi, and A. El Ghzizal, "The most used MPPT algorithms: Review and the suitable low-cost embedded board for each algorithm" J. Cleaner Prod., vol. 246, Feb. 2020, Art. no. 118983.

[15] S. Poshtkouhi, J. Varley, R. Popuri, and O. Trescases, "Analysis of distributed peak power tracking in photovoltaic systems," in Proc. Int. Power Electron. Conf., 2010, pp. 942-947.

[16] N. Femia, G. Lisi, G. Petrone, G. Spagnuolo, and M. Vitelli, "Distributed maximum power point tracking of photovoltaic arrays: Novel approach and system analysis," IEEE Trans. Ind. Electron., vol. 55, no. 7, pp. 2610-2621, Jul. 2008.

[17] S. Poshtkouhi, V. Palaniappan, M. Fard, and O. Trescases, "A general approach for quantifying the benefit of distributed power electronics for fine grained MPPT in photovoltaic applications using 3-D modeling," IEEE Trans. Power Electron., vol. 27, no. 11, pp. 4656-4666, Nov. 2012.

[18] K. Punitha, D. Devaraj, and S. Sakthivel, "Artificial neural network based modified incremental conductance algorithm for maximum power point tracking in photovoltaic system under partial shading conditions," Energy, vol. 62, pp. 330-340, Dec. 2013.

[19] H. Wang and J. Shen, "An improved model combining evolutionary algorithm and neural networks for PV maximum power point tracking," IEEE Access, vol. 7, pp. 2823-2827, 2019.

[20] H. Rezk, M. Aly, M. Al-Dhaifallah, and M. Shoyama, "Design and hardware implementation of new adaptive fuzzy logic-based MPPT control method for photovoltaic applications," IEEE Access, vol. 7, pp. 106427-106438, 2019.
[21] A. Messai, A. Mellit, P. A. Massi, A. Guessoum, and H. Mekki, "FPGAbased implementation of a fuzzy controller (MPPT) for photovoltaic module," Energy Convers. Manag., vol. 52, no. 7, pp. 2695-2704, 2011.

[22] T. L. Nguyen and K. S. Low, "A global maximum power point tracking scheme employing DIRECT search algorithm for photovoltaic systems," IEEE Trans. Ind. Electron., vol. 57, no. 10, pp. 3456-3467, Oct. 2010.

[23] H. Heydari-doostabad, R. Keypour, M. R. Khalghani, and M. H. Khooban, "A new approach in MPPT for photovoltaic array based on extremum seeking control under uniform and non-uniform irradiances," Sol. Energy, vol. 94, pp. 28-36, Aug. 2013.

[24] E. Moshksar, T. Ghanbari, H. Samet, and M. Guay, "Estimation-based extremum-seeking control: A real-time approach for improving energy efficiency in photovoltaic systems," IEEE Syst. J., vol. 13, no. 3, pp. 3141-3152, Sep. 2019

[25] K. Ishaque, Z. Salam, A. Shamsudin, and M. Amjad, "A direct control based maximum power point tracking method for photovoltaic system under partial shading conditions using particle swarm optimization algorithm," Appl. Energy, vol. 99, pp. 414-422, 2012.

[26] H. Li, D. Yang, W. Su, J. Lu, and X. Yu, "An overall distribution particle swarm optimization MPPT algorithm for photovoltaic system under partial shading," IEEE Trans. Ind. Electron., vol. 66, no. 1, pp. 265-275, Jan. 2019.

[27] M. Miyatake, M. Veerachary, F. Toriumi, N. Fujii, and H. Ko, "Maximum power point tracking of multiple photovoltaic arrays: A PSO approach," IEEE Trans. Aerosp. Electron. Syst., vol. 47, no. 1, pp. 367-380, Jan. 2011.

[28] R. B. A. Koad, A. F. Zobaa, and A. El-Shahat, "A novel MPPT algorithm based on particle swarm optimization for photovoltaic systems," IEEE Trans. Sustain. Energy, vol. 8, no. 2, pp. 468-476, Apr. 2017.

[29] N. Priyadarshi, S. Padmanaban, P. Kiran Maroti, and A. Sharma, "An extensive practical investigation of FPSO-based MPPT for grid integrated PV system under variable operating conditions with anti-islanding protection,” IEEE Syst. J., vol. 13, no. 2, pp. 1861-1871, Jun. 2019.

[30] L. L. Jiang, D. L. Maskell, and J. C. Patra, "A novel ant colony optimization-based maximum power point tracking for photovoltaic systems under partially shaded conditions," Energy Building, vol. 58, pp. 227-236, 2013.

[31] K. Sundareswaran, V. Vigneshkumar, P. Sankar, S. P. Simon, P. Srinivasa Rao Nayak, and S. Palani, "Development of an improved P\&O algorithm assisted through a colony of foraging ants for MPPT in PV system," IEEE Trans. Ind. Informat., vol. 12, no. 1, pp. 187-200, Feb. 2016.

[32] A. S. Benyoucef, A. Chouder, K. Kara, S. Silvestre, and O. A. Sahed, "Artificial bee colony based algorithm for maximum power point tracking (MPPT) for PV systems operating under partial shaded conditions," Appl. Soft Comput. J., vol. 32, pp. 38-48, Jul. 2015.

[33] K. Sundareswaran, P. Sankar, P. S. R. Nayak, S. P. Simon, and S. Palani, "Enhanced energy output from a PV system under partial shaded conditions through artificial bee colony," IEEE Trans. Sustain. Energy, vol. 6, no. 1, pp. 198-209, Jan. 2015.

[34] S. Hassan, B. Abdelmajid, Z. Mourad, S. Aicha, and B. Abdenaceur, "An advanced MPPT based on artificial bee colony algorithm for MPPT photovoltaic system under partial shading condition," Int. J. Power Electron. Drive Syst., vol. 8, no. 2, 2017, Art. no. 647.

[35] D. Shmilovitz and Y. Levron, "Distributed maximum power point tracking in photovoltaic systems-Emerging architectures and control methods," Automatika, vol. 53, no. 2, pp. 142-155, 2012.

[36] J. M. A. Myrzik and M. Calais, "String and module integrated inverters for single-phase grid connected photovoltaic systems - A review," in Proc. IEEE Bologna PowerTech Conf. Proc., 2003, vol. 2, pp. 430-437.

[37] F. Keyrouz and S. Georges, "Efficient multidimensional maximum power point tracking using bayesian fusion," in Proc. 2nd Int. Conf. Electric Power Energy Convers. Syst., 2011, pp. 1-5.

[38] V. Tereshko and A. Loengarov, "Collective decision-making in honey bee foraging dynamics," Comput. Inf. Syst., vol. 9, no. 3, pp. 1-7, 2005.

[39] V. Tereshko and T. Lee, "How information-mapping patterns determine foraging behaviour of a honey bee colony," Open Syst. Inf. Dyn., vol. 9, no. 2, pp. 181-193, Jun. 2002.

[40] V. Tereshko, "Reaction-diffusion model of a honeybee colony's foraging behaviour," in Proc. Int. Conf. Parallel Problem Solving Nature, 2000, vol. 1917, pp. 807-816.

[41] E. Garoudja, K. Kara, A. Chouder, and S. Silvestre, "Parameters extraction of photovoltaic module for long-term prediction using artificial bee colony optimization," in Proc. 3rd Int. Conf. Control, Eng. Inf. Technol., 2015, pp. 1-6. 